\title{
Search Engine Optimization Analyzing \& Interpreting the Necessity of SEO for Enterprises
}

\author{
Sachith Poojary ${ }^{1}$, Tanmay Narayan ${ }^{2}$, Rohini Temkar ${ }^{3}$ \\ MCA, VESIT, Mumbai University, Mumbai, India ${ }^{1,2}$ \\ Assistant Professor, VESIT, Mumbai, India ${ }^{3}$
}

\begin{abstract}
SEO is the method to induce your website higher rankings in search engines. SEO could be a necessary service because the web is evolving at a fast pace and there's bigger than before competition for market go to the highest positions in numerous search engines to achieve. Through analysis facilitate, it had been shown that almost all individuals like the primary 10 search outcome as if they traverse the list of search engines and infrequently select results. SEO is one of the foremost unmarked areas of selling these days. You're having the older generation still making an attempt to advertise on billboards, TV commercials, advertisements or radio. Within the meanwhile the younger people consumed with the hoopla of Facebook, Twitter and social networking websites. There are innumerable SEO techniques with very best quality that are ready to bring home the bacon of required results. SEO is the best content methodology that's for much longer term. You'll be able to climb within the rankings of Google inside days. Generally, it takes many months before seeing a lift in your position. However, on one occasion you'll be able to even get to the height of the search engines and you'll be able to even receive continuing stream traffic. The target of this analysis paper was to prove that implementing computer program optimization components that are increasing web site traffic and on-line visibility. For web site usability, SEO attributes is crucial to boost rankings.
\end{abstract}

Keywords: on page, off page, Meta keyword, Search Engine Optimization, SEO Techniques, Page Rank.

\section{INTRODUCTION}

Search engine improvement (SEO) has been around since the mid-1990s.with information. "SEO could be a system that facilitates search engines realize your web site and rank it above the legion alternative websites in response to a research question. SEO, therefore, makes it easier for you to induce a lot of traffic on your web site. Basically, it's regarding enhancing your site's ranking in numerous well-liked search engines like Google, Yahoo! and MSN. Computer program improvement is one of the foremost effective ways that to draw in a lot of relevant guests towards your web site."

Search Engine improvement (SEO) is simply the primary step of promoting your website. a mixture of proactive broadspectrum, nevertheless tightly targeted web selling efforts is crucial to obtaining your message to your potential customers. With a calculable 1.2 million websites being added to the web on a daily basis this has become a viciously competitive arena with everybody in shout for a primary page position on search engines. SEO is split into 2 sorts. the primary sort is termed white hat SEO or white SEO. The second is termed black hat SEO or black SEO. Those sorts are opposite one another. White SEO refers to a kind of SEO technique that involves legal ways to boost the visibility of an internet site or website in search engines. In alternative facet, black SEO refers to SEO technique that uses unethical ways to boost a website's visibility in computer program. Some concrete samples of black SEO are link farms and keyword stuffing computer program.

\section{How does a Search Engine Work?}

Search engines perform several activities in order to deliver search results.

Crawling - Process of fetching all the web pages linked to a website. This task is performed by a software called a crawler or a spider (or Googlebot, in case of Google).

Indexing - Process of creating index for all the fetched web pages and keeping them into a giant database from where it can later be retrieved. Essentially, the process of indexing is identifying the words and expressions that best describe the page and assigning the page to particular keywords.

Processing - When a search request comes, the search engine processes it, i.e., it compares the search string in the search request with the indexed pages in the database.

Calculating Relevancy - It is likely that more than one page contains the search string, so the search engine starts calculating the relevancy of each of the pages in its index to the search string. 
Retrieving Results - The last step in search engine activities is retrieving the best matched results. Basically, it is nothing more than simply displaying them in the browser. Search engines such as Google and Yahoo! often update their relevancy algorithm dozens of times per month. When you see changes in your rankings, it is due to an algorithmic shift or something else beyond your control.

Although the basic principle of operation of all search engines is the same, the minor differences between their relevancy algorithms lead to major changes in the relevancy of results.

\section{What is Search Engine Rank?}

When you search any keyword employing a computer program, it displays thousands of results found in its information. A page ranking is measured by the position of websites displayed within the computer program results. If a research engine is swinging your website on the primary position, then your website rank is no 1 and it'll be assumed as the page with the best rank. SEO is that the method of coming up with and developing an internet site to realize a high rank in computer program results.

\section{SEO PROCSESS}

There are several segments of SEO strategy seen as optional that are actually absolutely imperative to the success of an SEO campaign Website analysis.

- Competitive Analysis.

- Proper Keyword Research.

- Content Development.

- On-page Optimization.

- Off-page Optimization.

- Return on Investment Analysis.

- Local SEO.

- Daily, weekly and monthly reports.

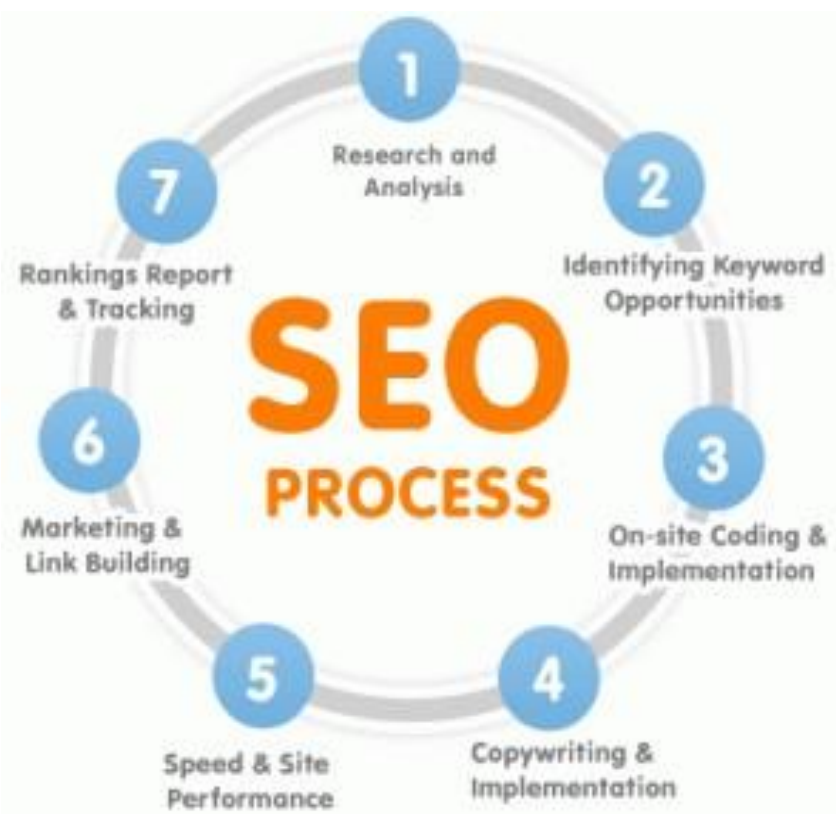

Fig1. SEO Process

\section{TYPES OF SEO:}

Main two types of SEO are:

On page optimization

Off page optimization

\section{On page optimization}

On page optimization is the process of making a website SEO friendly and lot of points keep in mind when we doing the on page of any website like title tag optimization, meta description of that website, navigation structure of a website and more. 
UGC Approved Journal

IARJSET

ISSN (Online) 2393-8021 ISSN (Print) 2394-1588

International Advanced Research Journal in Science, Engineering and Technology ISO 3297:2007 Certified

Vol. 4, Issue 7, July 2017

\section{Off page optimization}

Off Page Optimization is the activity that is done on other sites for our site to increase search engine ranking. Off page is what you do to promote your website like link building, social bookmarking, blog posting, directory submission, smo etc. SEO techniques are classified into two broad categories:

White Hat SEO - Techniques that search engines recommend as part of a good design.

Black Hat SEO - Techniques that search engines do not approve and attempt to minimize the effect of. These techniques are also known as spamdexing.

\section{Latest SEO Techniques to Drive Targeted Traffic to Your Website}

Even though individuals spend lots of their online time on social network sites, search engines like Google, Bing and Yahoo, are still the first drivers of traffic to plenty of internet sites. More or less eightieth of traffic on the web is owing to search engines. One of the simplest SEO techniques is Keep changing Your web site as search engines index those websites quickly \& rank them higher that are updated often. When Google Panda Update content is termed as King to rank higher on the search engines. Take care regarding the density of keywords and phrases and maintain a balance between what guests and search engines wanting, you wish to continuously quote your diary or web site. Organizing on-line contests giving a prize for the simplest internet style, or the simplest style of an emblem, continuously offers content to the organizer. Therefore, use your own ways that can be known as this can increase traffic to your web site. Publish regarding your web site or diary in newspapers, magazines, etc., Attend conferences and seminars. If someone scan your article within the newspaper is extremely probable that visits your website. Word of mouth remains an efficient technique to push your web site.

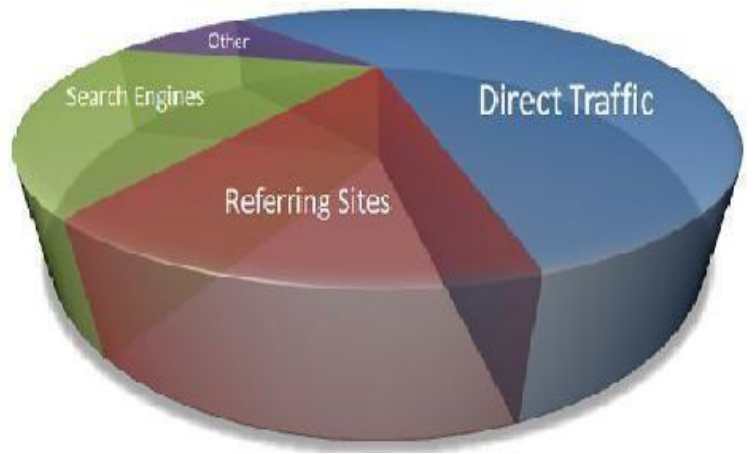

Fig 2 show traffic drive different category

How does Modern SEO technique work?

Search engines have existed for about 2 decades now, and many people know how they work. Up until a few years ago, SEO used to be a simple case of finding some keywords and then building links based on them. This resulted in a lot of spam and low-quality search results on Google.

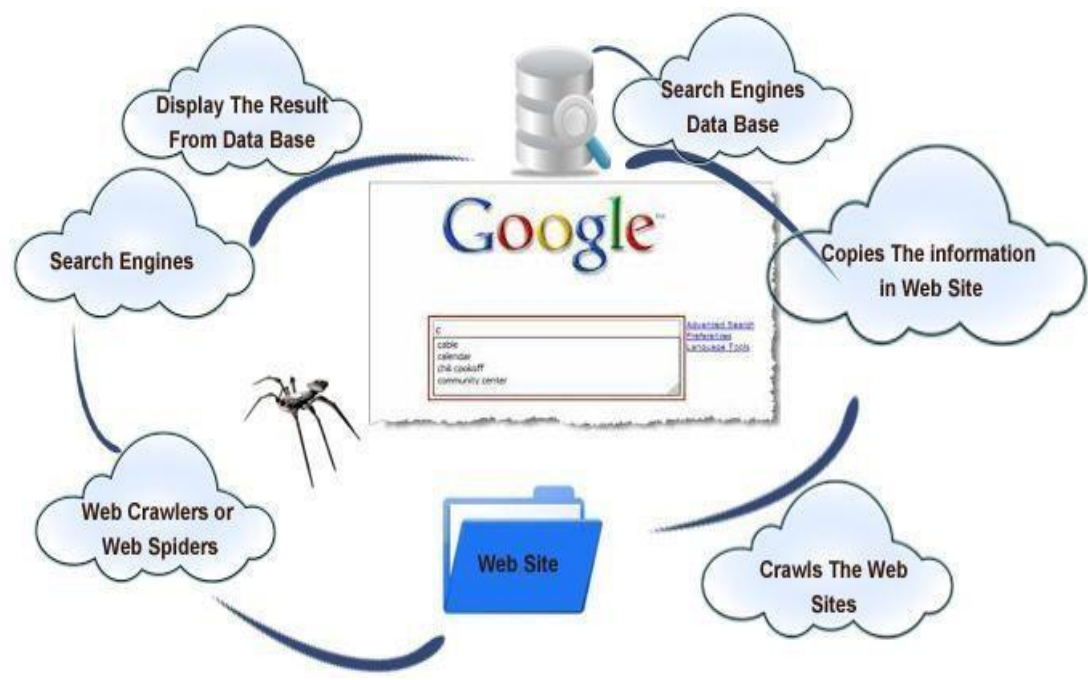

Fig 3 show how search engine work 
Search engines have updated their algorithms to detect unethical SEO tactics. Most websites that used shady methods to increase their ranks on search engines were severely penalized. Here are some SEO techniques that used to work but do not anymore:

- Building links through link farms

- Building links through content farms

- Stuffing articles and web pages with keywords

- Building an excessive number of links in a short period of time

- Using various article marketing techniques and ignoring all other legitimate techniques

There are better ways to optimize your website and make them more popular on search engines. Here are some techniques that do work.

\section{Guest posting}

This is a recent technique and it's grown to be very talked-about over the last 3-4 years. Guest posts are revealed on websites and blogs aside from yours. They need attention-grabbing content for readers of the web site.

\section{Why Do I Need Guest Blogging?}

Positive and constructive comments from consumers help maintain a respectable business image, and they are also a valuable advertising method. Improve your site's rankings and increase your incoming traffic. The guest post contains links to your website that readers can follow. Your website is exposed to a wider audience, which can drive further traffic Guest posts are usually of higher quality. Guest posting improve rank through search engine holders.

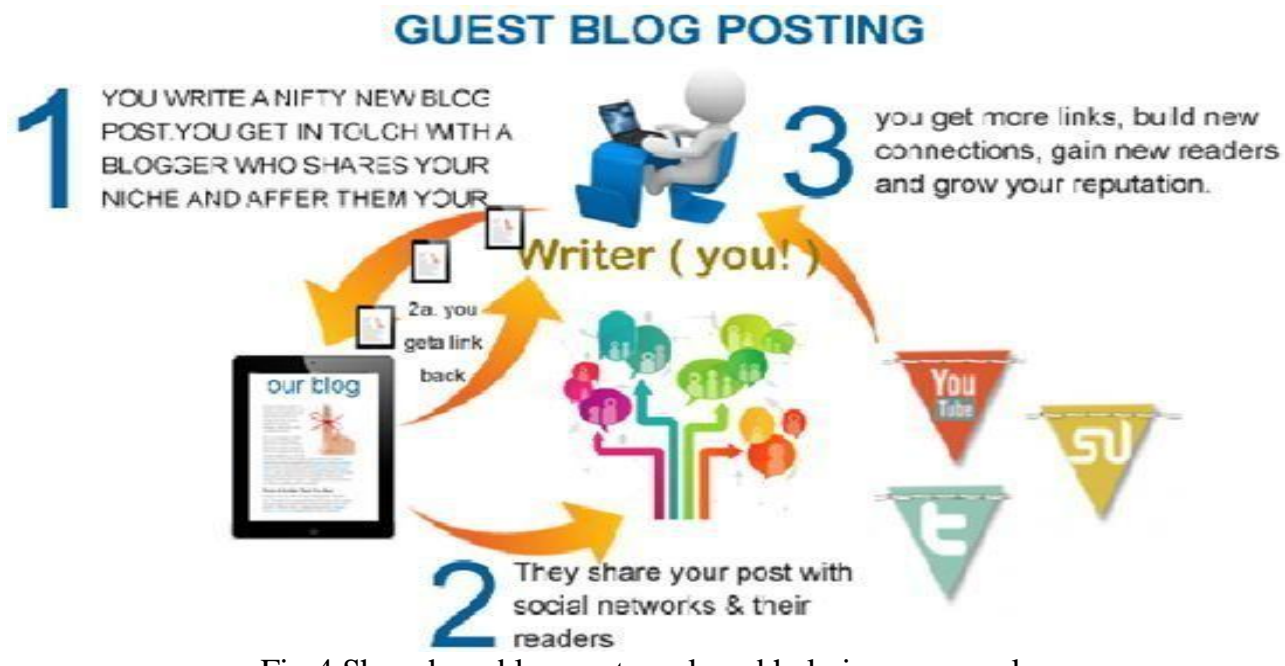

Fig 4 Show how blog post work and help improve rank

\section{Blogging}

Although social network has supplemented blogging to an outsized extent, it's still the simplest thanks to increase audience. Social network posts are terribly casual and that they are nice for conversations. However, after you post blogs that have real and attention-grabbing content, individuals are a lot more inquisitive about reading them.

\section{Facebook activity}

Facebook is a constant in people's lives. They use the network to find out what's going on around the world. They use it to find interesting news and you can use this to promote your products as well. Posting regular discounts and offers on Facebook will garner more attention and drive traffic to your website.

\section{Leveraging Twitter}

Twitter is probably the most impactful SEO tool in the last 3 years. It started as a small status update network, Tweets are short and they are more easily digestible for visitors.

Link building

Along with proper keyword research, link building forms one of the pillars of search engine optimization. The basic principle used by all search engines to gauge your popularity is still counting the number of links that point to your website. However, the rules have changed considerably over the last 3 years. 
Here are what search engines want from your website:

- Backlinks to your website must be organic (and not part of an excessive strategy)

- Links should appear on quality websites (as determined by their PageRank)

If many links are found on your website on link farms and content farms, Google and Bing will downgrade your rankings severely. High quality link building will lead your web pages to appear in the top 10 or 20 search results on search engines

\section{Using niche long tail keywords}

People increasingly search on mobile devices. Earlier, people used to only look for information about certain topics on the internet. Today, they use it to look for:

- Products and services

- Nearby restaurants, movies and other places

Search is becoming increasingly localized. Therefore, if your business is based on Melbourne, you need to include those locations in your keyword research as well. Examples include:

Red running shows in Melbourne (rather than simply "red running shows")

You need to use generic keywords as well as long tail niche keywords as mentioned above. This will help your website appear on top when people are looking for local places and businesses.

\section{Upgrade your website}

The last 3 years have seen modern web standards including HTML5 and CSS3 emerge. These technologies make it easier for search engines to parse your website content and index information. Upgrading our website is the single best thing you can to do increase your visibility on search engines.

\section{Maintain your links}

As time goes on, many websites are simply not updated. Some websites go down. Even in existing websites, some pages are deleted. However, the links to these pages are not always taken down. These are called dead links and the resulting state is called link rot.

You need to confirm that every one of the links on your websites are active and dead links are removed. You do not have to be compelled to go explore for individual links as a result of there are several tools that may assist you modify this method. Running through this method weekly can facilitate make sure that search engines continuously realize your web site to be prime quality.

\section{Update your website activity}

Finally, search engines wish websites to move. If your website isn't often updated with new content, it's thought-about to be inactive and so of very little price to look engine users. Keep your web site contemporary with new posts and style, therefore Google and alternative engines can index your web site on a day after day. This way, users will get the newest content on your web site from search engines. SEO has so become an awfully time overwhelming job, however that's as a result of such a large number of factors. You would possibly wish to rent a reliable SEO company to assist you type a concrete strategy.

\section{WHY IS SEO IMPORTANT?}

We are well acquainted with the fact that developing your business online is not just having a website. SEO is like electrical energy for your online firm, and making business through your site does not take place on its own. Most of the users who are in search of your products or services utilize a Search Engine such as Google to come across you and your contenders. Now, if your website does not have an ongoing / current SEO strategy, you obstruct the ability for your site to be located over the search engines like Google

\section{Why do we need Ongoing SEO?}

Ongoing SEO is important because the search engine industry changes very often.

It helps organizations to proactively build links over time.

It helps you to frequently view and analyze the analytics.

Regular reporting and evaluation ensure objectives are being achieved or at least moving in the right direction.

\section{Is on-page SEO more important than off-page SEO?}

On-page is something you directly management within the code or content of your website. On-Page or on-the-scene improvement may be useful as probing for sensible rankings for your web site or diary and might be crucial after you are near obtaining that final position in Google. However, in the course of the method of obtaining your website to no 1 
you must still pay close attention to on-the-scene optimization. However, it's Off-Page or off-site improvement that's very vital to obtaining sensible rankings in Google. In order to start out thinking on however you'll be able to promote your web site you should make sure that the web site is optimized and in good shape. The start is to figure with on-thescene SEO initial then go off-site. all of your web site content - pages, blogs, articles, etc. Title tags, meta tags, and H1 tags Your computer program, layout, and every one aspects of style elevation text for your pictures. The keywords you employ, and their usage density (do not assume a lot of is better) however contemporary, unique, and current your content is that the time it takes for your web site to load uniform resource locator structure, and whether or not or not the URLs contain your keywords XML websitemap - it ought to be comprehensive and dynamic A full compartmentalization of your site (you will choose pages that you just don't want to be indexed by search engines) Internal linking (linking to alternative pages inside your site) and navigation Robots.txt file (this tells the search engines to index your site).

\section{Off-site}

Off-site SEO is therefore all the link building and marketing techniques you employ outside the context of your own website. These include (but are not limited to):

- Link building; back-linking and inbound

- Press releases and other media articles that directly reference your website

- Any article directory submissions you have made

- Competitor analysis

- Your social media posts and related marketing

- Keyword analysis - the popularity and accuracy of your keywords

- Leaving comments and links on other sites, blogs, forums, and videos

- Submissions to SEO-friendly directories

- Videos placed on sites like YouTube, properly optimized

- RSS feeds

- AdWords and other paid keyword campaigns

- Trackbacks

\section{ADVANTAGES OF SEO}

The primary advantage of SEO over any other type of internet marketing. Once your site is ranked in the top 10 for your keyword phrase, you should be able to keep it there with a minimum of fuss. This means that you will receive free traffic as long as you keep it up

\section{Superb ROI}

Return on investment is one of the major advantages of SEO over paid advertising. A site takes some time to get rank and after the site ranked, the ROI will be great.

\section{COST EFFECTIVENESS}

SEO is one of the most cost-effective ways of marketing. If the site is properly designed and optimized then it has a longer standing compared to the Pay Per Click Advertising.

\section{BETTER USABILITY}

The site is easily available to the large portion of the online users. A better optimized and designed website always attracts lot of visitors

\section{HIGHER SALES}

Increased visibility, cost effectiveness and accessibility leads to the higher sales.

\section{$60 \%$ Of Clicks Go to the First Result}

This means that only $40 \%$ of clicks are left for the second through the millionth result on google for the keyword. Securing that top spot on Google is a sure-fire way to gain thousands upon thousands of visitors. SEO is certainly the tool needed to gain that top spot as well. For a small upfront investment, you are looking at potentially millions of sales.

\section{The Results are Low Cost (In Comparison to AdWords and PPC)}

Organic listings are essentially free. When you are listed at the top, you don't need to pay per click or allocate a budget for advertising, one of the main benefits of SEO is that it is the gift that keeps on giving. With a little bit of effort (and 
some money upfront to pay for SEO costs) you can watch your website get consistent traffic. You don't have to pay $\$ 10$ for every person who clicks on your ad. Unlike paid ads, your traffic will not drop to nothing when it stops. SEO gets rid of the need to have thousands of ads across the web.

\section{CONCLUSION}

In this paper, we tend to use some technique on page and off page for improve ranking website and that we bestowed some difficult drawbacks long-faced by existing search engines. For higher computer program Ranking, there is importance of each on-page and off-page SEO. There are several of Off-Page computer program improvement Techniques. This analysis is predicated on reviewing totally different obtainable techniques for optimizing individual web-pages or the whole web site to form them in a computer program friendly manner. Finally, we've got to conjointly prompt our own determined ways for computer program improvement. As a future dimension to the current analysis, we tend to shall develop an efficient and correct system for computer program improvement for getting the next rank for the web sites within the search results.

\section{REFERENCES}

[1] Sergey Brin and Lawrence Page, "The Anatomy of a Large-Scale Hypertextual Web Search Engine".online. Available: http://infolab.stanford.edu/ backrub/google.html

[2] Ayush Jain, Meenu Dave, "The Role of Backlinks in Search Engine Ranking" International Journal of Advanced Research in Computer Science and Software Engineering Volume 3, Issue 4, April 2013”.online.Available: http://ijarcsse.com/docs/papers/Volume_3/ 4_April2013/V3I4-0356.pdf

[3] Meng Cui, Songyun Hu, "Search Engine Optimization Research For Website Promotion, Transport Management College, Dalian Maritime University, Dalian, 116026, China".online. Available:http://www.ftsm.ukm.my:8080/kt/attachments/article/69/06113701.pdf

[4] "Search Engine Optimizationl”.online. Available: http://en.wikipedia.org/wiki/Search_engine_optimization [5] "Article Submission".online. Available: http://www.neyox.co.in/article-submission/

[6] “21 Off-Page SEO Strategies to Build Your Online Reputation”. Online. Available: http://www.seomoz.org/ugc/21offpage-seo-strategies-tobuild-your-online-reputatio

[7] K. ur Rehman and M. N. Ahmed Khan “ The Foremost Guidelines for Achieving Higher Rankingin Search Results through Search Engine Optimization" International Journal of Advanced Science and Technology Vol. 52, March, 2013

[8] P. Chahal, M. Singh and S. Kumar "Ranking of Web Documents using Semantic Similarity" Information Systems and Computer Networks (ISCON), 2013 International Conference on C2013 IEEE, DOI 10.1109/ICISCON.2013.6524191 Page(s): 145 - 150

[9] Using Search Engine Optimization Technique Increasing Website Traffic and Online Visibility" International Journal of Advanced Research in Computer Science and Software Engineering Vol. 5, Issue 1, January 2015

[10] M. Cui, S. Hu "Search Engine Optimization Research for Website Promotion" Information Technology, Computer Engineering and Management Sciences (ICM), 2011 International Conference on (Volume:4 ) @ 2011 IEEE, DOI 10.1109/ICM.2011.308Page(s):100 - 103 